mansasa

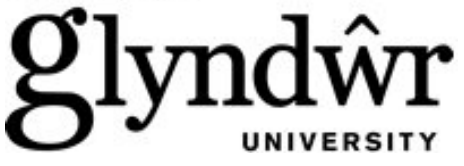

Glyndŵr University

Glyndŵr University Research Online

Aeronautical Engineering

Engineering

$12-1-1998$

\title{
Investigation of the Micromechanics of the Microbond Test
}

Richard Day

GlyndwrUniversity, r.day@glyndwr.ac.uk

J V. Cauich Rodrigez

Manchester Materials Science Centre

Follow this and additional works at: http://epubs.glyndwr.ac.uk/aer_eng

Part of the Aeronautical Vehicles Commons, Applied Mechanics Commons, Catalysis and Reaction Engineering Commons, Materials Chemistry Commons, Other Aerospace Engineering Commons, Other Chemical Engineering Commons, Other Civil and Environmental Engineering

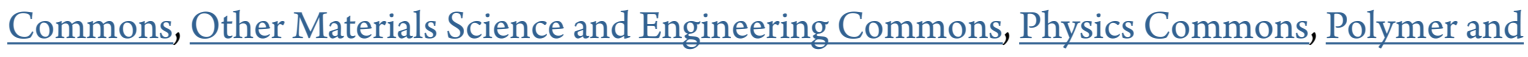
Organic Materials Commons, Polymer Science Commons, Structural Materials Commons, and the Structures and Materials Commons

\section{Recommended Citation}

Day, R.J. and Cauich Rodrigez, J.V. (1998), 'Investigation of the Micromechanics of the Microbond Test'. Composites Science and Technology, Vol. 58, Issue 6, pp 907-914

This Article is brought to you for free and open access by the Engineering at Glyndŵr University Research Online. It has been accepted for inclusion in Aeronautical Engineering by an authorized administrator of Glyndŵr University Research Online. For more information, please contact d.jepson@glyndwr.ac.uk. 


\title{
Investigation of the Micromechanics of the Microbond Test
}

\begin{abstract}
The microbond test is a method which is sometimes used for measuring interfacial shear strength. In the analysis of the data it is often assumed that the interfacial shear stress is constant and thus, by implication, that the strain in the fibre along the embedded fibre decreases linearly from the point of entry to the point of exit. In this paper the results of conventional microbond tests and simulated microbond tests performed under a Raman microscope on a Kevlar-49/epoxy system are reported. The conventionally performed tests show that the calculated interfacial shear strength for this system is approximately $16 \mathrm{MPa}$ regardless of the position of the supporting knife edges. The strain distribution along the fibre during simulated microbond tests was studied as a function of knife edge position, interfacial area and level of load by means of Raman spectroscopy. It was found that the interfacial shear stress was not constant, as is frequently assumed, but was strongly dependent upon distance through the droplet, knife-edge position and applied load. At low loads the strain was a maximum at the point where the fibre entered the droplet and then dropped off sharply through the embedded length. This effect was enhanced when the knife-edge separation was reduced. The variation of the shape of the stress distribution was similar to that predicted by a linear finite element analysis. At higher load levels the onset of failure in the region closest to the point where the fibre entered the droplet could be observed.
\end{abstract}

\section{Keywords}

aramid fibre, interface, interfacial strength; FEA, Raman spectroscopy

\section{Disciplines}

Aeronautical Vehicles | Aerospace Engineering | Applied Mechanics | Catalysis and Reaction Engineering | Chemical Engineering | Chemistry | Engineering | Materials Chemistry | Materials Science and Engineering | Mechanical Engineering | Other Aerospace Engineering | Other Chemical Engineering | Other Civil and Environmental Engineering | Other Materials Science and Engineering | Physics | Polymer and Organic Materials | Polymer Science | Structural Materials | Structures and Materials

\section{Comments}

Copyright (C) 1998 Elsevier. All rights reserved. This is the author's final version of the work after peer review. The article was originally published in Composites Science and Technology in 2008 by Elsevier. The full published article can be found at http://dx.doi.org/10.1016/S0266-3538(97)00197-8 on the publisher's website http://www.sciencedirect.co 


\title{
Investigation of the Micromechanics of the Microbond Test
}

\author{
R.J. Day and J.V. Cauich Rodrigez, \\ Manchester Materials Science Centre, \\ Grosvenor Street, \\ Manchester.
}

M1 7HS

\begin{abstract}
The microbond test is a method which is sometimes used for measuring interfacial shear strength. In the analysis of the data it is often assumed that the interfacial shear stress is constant and thus, by implication, that the strain in the fibre along the embedded fibre decreases linearly from the point of entry to the point of exit. In this paper the results of conventional microbond tests and simulated microbond tests performed under a Raman microscope on a Kevlar 49/epoxy system are reported. The conventionally performed tests show that the calculated interfacial shear strength for this system is approximately $16 \mathrm{MPa}$ regardless of the position of the supporting knife edges. The strain distribution along the fibre during simulated microbond tests was studied as a function of knife edge position, interfacial area and level of load using Raman spectroscopy. It was found that the interfacial shear stress was not constant, as is frequently assumed, but was strongly dependent upon distance through the droplet, knife edge position and applied load. At low loads the strain was a maximum at the point where the fibre entered the droplet and then dropped off sharply through the embedded length. This effect was enhanced when the knife edge separation was reduced. The variation of the shape of the stress distribution was similar to that predicted by a linear finite element analysis. At higher load levels the onset of failure in the region closest to the point where the fibre entered the droplet could be observed.
\end{abstract}

\section{Keywords}

Aramid fibre A, Interface B, Interfacial Strength B, FEA C, Raman spectroscopy D 


\section{Introduction}

Fibre reinforced composites can exhibit outstanding properties compared to their constituents. The fibre, matrix and interface are all important factors in the performance of composites. In particular the effective utilisation of the strength and stiffness of the fibres depends upon efficient transfer of load through the interface and, therefore, good interfacial bonding. Toughness, on the other hand, can be promoted by the use of a weaker interface, as is the case in many ceramic matrix composites. Thus the measurement and control of bond strength between the fibres and matrix is important and has been the subject of much effort. The interfacial shear strength of composites can be measured by tests on single fibre systems[1-13]. It is noticeable, however, that the various tests give different results even when used to characterise the same system[14-15]. Of the single fibre methods the most commonly used has been the pull-out technique[1-8]. A limitation to this approach is that if the fibre embedded length is longer than the critical length then failure of the fibre will occur before pull out. The manufacture of samples with sufficiently short embedded length is difficult. A modified technique, the microbond test, has been proposed in order to surmount this problem[12-13]. The sample preparation for this test involves the application of a microdroplet of resin onto the fibre. The microdroplet is then restrained by knife edges whilst the fibre is pulled out. It is usual to assume that the shear stress is constant along the interface so that the interfacial shear strength is calculated from the debonding force divided by the interfacial area. This should lead to a linear relationship between debonding force and embedded length. This relationship is observed if the embedded length is small, but at higher embedded lengths the debonding force tends to a maximum. This indicates that the assumption cannot be correct. Indeed theoretical and finite element studies show that the interfacial shear stress is not constant throughout the specimen[16-19]. It is clear that experimental measurements of the strain and interfacial stress distributions along the interface during the microbond test are required in order to put the theory and data reduction method on a firmer footing.

It has been found that the frequency of the bands in the Raman spectrum of many materials is sensitive to the stress in that material. There are a large number of reports which show that Raman spectroscopy can be used to measure strain and shear stress in fibres and composites. Examples of such studies may be found in 
references 20 to 34 . Kevlar fibres have been the subject of a number of these studies as single fibres, in composites and during micromechanical tests[18,24,25-34]. There has been some confusion in the literature since some authors have not found changes in the Raman spectrum of Kevlar when the fibre was loaded[35-36]. These authors used high powered Argon ion lasers whereas those who found shifts used helium neon lasers[21-27,29-32]. It is now clear that the 488nm line of argon ion lasers causes erratic Raman peak shifts and premature failure when used to excite Raman spectra from Kevlar fibres[21]. In this work Raman spectroscopy has been used to obtain the strain distribution along a fibre within a droplet during simulated microbond tests using a helium neon laser and from these data the interfacial shear stress distributions have been determined.

\section{Experimental}

Microbond tests were carried out using an Instron mechanical testing machine in order to provide a comparison between the Raman data and the conventional approach. The Kevlar fibres were mounted singly upon paper cards with windows cut in them using double-sided adhesive tape. The fibres were subsequently fastened with a slow setting, cold-curing epoxy adhesive. The fibre droplet specimens were prepared by depositing a small amount of epoxy resin onto a horizontally suspended Kevlar fibre. The epoxy resin used was Ciba-Geigy LY1927 and the hardener was HY1927. These were mixed in the recommended ratio of 100:36 parts by weight and cured at room temperature. The resin was placed on the fibre using a fine glass applicator under a magnifier. The embedded length and droplet diameter were measured for each sample under an optical microscope. Microbond tests were performed using the mechanical testing machine. The free end of the fibre was held in a standard fibre testing grip. The microdroplet was restrained using two knife edges. The separation of these was controlled by means of a micrometer. A schematic drawing of the arrangement is shown in figure 1.

The Raman spectroscopic measurements were performed using a SPEX $1000 \mathrm{~m}$ single spectrometer coupled to a modified Olympus BH-2 optical microscope. Additional rejection of the laser line was provided by a holographic filter placed between the microscope and spectrometer. A Wright Instruments CCD camera was used as the detector. Spectra were excited with the $632.8 \mathrm{~nm}$ line of a $7 \mathrm{~mW}$ helium 
neon laser. The power at the sample was less than $1 \mathrm{~mW}$. The beam was focused on the sample through the microscope using a x20 objective lens with a numerical aperture of 0.4 . The beam was polarised parallel to the fibre axis for all measurements and the exposure time was ten seconds. Prior to the simulated microbond experiments a number of calibration curves of strain versus Raman frequency were obtained. Single Kevlar fibres were fastened to a purpose built straining rig consisting of one fixed and one moveable block. The later was displaced by a micrometer, thus giving a measurement of fibre strain. Spectra of the $1610 \mathrm{~cm}^{-1}$ band were taken at $0.1 \%$ increments in fibre strain. The gauge length of the samples was approximately $20 \mathrm{~mm}$.

The simulated microbond tests were carried out using a straining rig which was modified from the one used for the single fibre calibration measurements. A schematic diagram of this rig is shown in figure 2. The stationary block was replaced by two adjustable knife edges which allowed the resin droplet to be restrained with different knife edge separations. For these experiments gaps of 20,50 and $80 \mu \mathrm{m}$ were used. The end of the fibre was fastened to the moveable block in a similar manner as in the single fibre tests. The fibre was strained to a number of levels of strain and at each spectra were taken from the embedded fibre. Spectra were taken at $10 \mu \mathrm{m}$ intervals in the first $100 \mu \mathrm{m}$ from the point were the loaded fibre entered the droplet, then at $30 \mu \mathrm{m}$ intervals after that. Spectra were also taken from the area either side of the knife edges and also from the loaded fibre. Samples with droplets from $100 \mu \mathrm{m}$ to $600 \mu \mathrm{m}$ in length were used.

Finite element simulation of the microbond test to observe the effect of the knife edge separation upon the form of the shear stress distribution along the interface. This was undertaken using the LUSAS finite element system from FEA Ltd. A linear-elastic axisymmetric model was used. The axial modulus of the fibre was assumed to be 121.5 GPa and the transverse modulus $2.49 \mathrm{GPa}$ [37]. The shear modulus of the fibre was taken to be $1.69 \mathrm{GPa}$ [38]. The resin Youngs modulus was assumed to be $3 \mathrm{GPa}$.

\section{Results and Discussion}

Conventional analysis

Conventional microbond tests were carried out using an Instron mechanical tester as 
described above. The droplets were supported using knife edges. One of these was moved by means of a micrometer so that the separation between them could be set. Experiments were carried out using knife-edge separations of 20,50 and $80 \mu \mathrm{m}$. Figures 3-5 show plots of pull-out force against embedded area data obtained with these knife edge separations. According to Miller, Muri and Rubenfeld [13] the shear stress can be assumed to be constant along the interface and thus the interfacial shear strength can be found from

$$
\tau=\frac{F}{2 \pi r l}
$$

Equation 1

were $F$ is the failure force, $r$ is the radius of the fibre, $l$ is the embedded length and hence $2 \pi r l$ is the embedded area. Straight lines have been fitted to the failure force against interfacial area data in figures 3-5. Only the data at low embedded areas were used for this because as the embedded area increases the data tends towards a constant value of force. At this constant level of applied force it is quite possible that the fibre is failing rather than interfacial yielding or debonding occurring. The fits have been forced to go through the origin since it is clear from Equation 1 that the force must be zero when the embedded area is zero. The straight line fits yield values of average interfacial shear strengths of $15.7,15.8$ and $15.5 \pm 3.0 \mathrm{MPa}$ for tests with the knife edge separations of 20,50 and $80 \mu \mathrm{m}$ respectively. Thus the position of the knife edges appeared to have no effect upon the measured value of interfacial shear strength. This should be compared to the data obtained from simulated microbond tests using Raman spectroscopy, presented in the next part of the paper, which shows a significant variation in the interfacial shear stress distribution depending upon the position of the knife edges.

\section{$\underline{\text { Raman investigations of microbond samples at low strain levels }}$}

In order to investigate in more detail the micromechanics of the microbond tests Raman microscopy was used to measure the stress distribution along the interface. In order to use this approach it is necessary to calibrate the rate of shift of one of the Raman bands with strain for a single fibre. This was accomplished using a small straining rig as described above. Figure 6 shows a calibration plot for a single Kevlar fibre. The average slope measured was $4.85 \mathrm{~cm}^{-1} \%^{-1}$ which is in good agreement with 
previously published values[21,31].

Simulated microbond tests were performed using a rig similar to that used for calibrating the single fibres as described earlier. The simulated microbond tests were difficult in general to perform. Raman spectra were obtained from a number of specimens with different embedded lengths to investigate the effect of embedded length on the strain distribution along the interface and upon the interfacial shear stress distribution. The effect of knife edge separation upon these distributions was also investigated. The simulated microbond test samples all failed by debonding except in one case where the embedded length was $500 \mu \mathrm{m}$ and the knife separation was $20 \mu \mathrm{m}$ which failed by fibre fracture. Since only one sample failed this way this may have been due to the high stress on the fibre at the point of entry caused by the support conditions or by rubbing of the fibre against the knife edge.

Figure 7 shows typical results from some simulated microbond tests. Three strain profiles are presented each taken with knife edge separations of 20,50 and $80 \mu \mathrm{m}$. The external fibre strain was between 0.6 and $0.9 \%$ for these data. Information with fibres at exactly the same strain was not obtained due to the difficulties in making the measurements. The droplets in each case were approximately $500 \mu \mathrm{m}$ long. There is some scatter in the data, but it can be seen that the strain in the fibre is a maximum close to the point where the loaded fibre enters the droplet and the strain rapidly decreases along the length of the droplet. This is as might be expected from shear lag theory[39,40], but is contrary to the assumption made in the simple analysis of the microbond test[12,13], that the shear stress is constant. In order for the shear stress to be constant the decrease of strain with distance through the droplet should be linear, which is not the case as shown by figure 7 .

The pull-out test has been modelled by a number of workers. The general form of these models is very similar. Piggott[17] gives the strain along the fibre, $\varepsilon_{f}$, as

$$
\varepsilon_{f}=\varepsilon_{a p p} \frac{\sinh \left[n\left(L_{e}-x\right) / r\right]}{\sinh (n s)} \quad \text { Equation } 2
$$

where $\varepsilon_{a p p}$ is the external strain on the fibre, $r$ is the radius of the fibre, $L_{e}$ is the embedded length, $S$ is the aspect ratio of the fibre, i.e. $L_{e} / r$ and $n$ is given by the formula 


$$
n^{2}=\frac{E_{m}}{E_{f}} \frac{1}{\ln (R / \mathrm{r})} \frac{1}{\left(1+v_{m}\right)}
$$

where $E_{m}$ is the Young's modulus of the matrix, $E_{f}$ is the fibre Young's modulus, $R$ is the radius of the block of resin surrounding the fibre, $r$ is the radius of the fibre and $v_{m}$ is the Poisson's ratio of the matrix

In order to ascertain whether or not the theory predicts the form of the data, Equation 2 has been plotted with the strain data obtained from a droplet of length $540 \mu \mathrm{m}$ in figure 7. It can be seen in figure 7 that Equation 2 fits the data reasonably well. In order to plot these curves a value for $n$ of 0.11 was used for the data gathered with knife edge separations of 20 and $50 \mu \mathrm{m}$ and 0.07 for the data obtained with a knife edge separation of $80 \mu \mathrm{m}$. The difference in the value of $\mathrm{n}$ required to fit the data where the droplet was gripped further away from the fibre suggests that at this point the influence of the knife edges upon the strain and interfacial stress distributions is less marked. The significance in the different values of $n$ required to fit the data is not high, however, and thus $\mathrm{n}$ should be regarded as little more than a fitting constant. Although the theory was developed for the pull-out rather than microbond test the geometry is similar and the fit to the experimental data can be seen from figure 7 to be good.

\section{Geometrical effects}

Closer inspection of figure 7 reveals that the slope of the curves for different gripping positions is not the same. The rate of decrease of fibre strain with distance into the droplet is lower for the droplet restrained with an $80 \mu \mathrm{m}$ knife edge gap than for the ones where the knife edge separation was 20 or $50 \mu \mathrm{m}$. In order to fit the data, as noted above, a different value of $\mathrm{n}$ was required. This difference is, as stated previously, presumably due to the influence of the stress concentration of the knife edge at the lower separations.

Perhaps clearer is the data presented in figure 8 which shows the interfacial shear stress as a function of position through the droplet. This was calculated from the data of figure 7 using the expression[41]

$$
\tau_{x}=\frac{E_{f} d}{4} \frac{\mathrm{d} e_{f}}{\mathrm{~d} x}
$$

Equation 4

where $\tau_{x}$ is the interfacial shear stress, $E_{f}$ is the fibre Young's modulus, $d$ is the fibre 
diameter and $\mathrm{de} f / \mathrm{d} x$ is the slope of the strain against distance curve. These data show that the interfacial shear stress is high at the point of entry of the fibre into the droplet and then decreases rapidly with distance through the droplet.

Figure 8 shows that the interfacial shear stress at the point of fibre entry into the droplet increases as the knife edge supports are moved closer in towards the fibre. There is thus an influence on the strain and stress distributions of the gripping position. In order to verify the stress distributions obtained from the Raman spectroscopy experiments and to model the effect of knife edge position upon the strain distributions a simple, linear axisymmetric finite element analysis has been performed. In this analysis the gripping position was moved around the droplet one node at a time from the fibre outwards. The mesh which was used is shown in figure 9 . Figure 10 shows the strain distribution in the droplet as a function of the gripping position predicted by the finite element analysis. The external fibre strain used for these calculations was 1 $\%$. Comparison of this with figure 7 shows good agreement on the shape of the stress distribution, thus confirming the experimental measurements. It is clear from these measurements and calculations that the interfacial shear stress in the droplet will not be constant, as is usually assumed in the analysis of data from this test.

Figure 11 shows the effect of droplet length on the strain distribution in the embedded part of the fibre. In this figure the separation of the knife edges has been maintained at $80 \mu \mathrm{m}$. It can be seen from figure 11 that for the embedded lengths examined that the strain distributions are similar in nature to those observed in figure 7. The strain decreases throughout the droplet, but this decrease is not linear and, therefore, cannot give a constant shear interfacial shear stress. The form of this decrease is similar in each of these cases and not dissimilar to the form of the shear lag and finite element[17,19,30] predictions.

\section{High strain deformation}

So far all of the strain and shear stress distributions presented and discussed have been recorded with the strain in the loaded part of the fibre being $1 \%$ or less. Thus the specimen is not close to failure and the matrix is still behaving elastically. The stress distributions close to failure might be expected to be different to these initial ones. This is true for this system and figure 12 shows the strain distribution in a $440 \mu \mathrm{m}$ long droplet, with the knife edges $50 \mu \mathrm{m}$ apart at different levels of applied stress. It can be 
seen from this figure that the strain distribution within the fibre at low strain levels is very much like those observed in the previous figures. Indeed the lines shown on figure 12 for the two curves at lower strain were drawn using equation 2 with the same value of $n$ as used for the data of figure 7 restrained at $50 \mu \mathrm{m}$ knife edge gap. With higher levels of strain in the loaded part of the fibre it can be seen that the form of the strain distribution changes significantly. There is a region where the strain decreases linearly followed by a region in which there is shear lag type behaviour. The data is of the form expected where there is partial debonding of the interface. The debonding takes place over the initial portion of the embedded fibre, up to $250 \mu \mathrm{m}$, this is then followed by elastic stress transfer. Previous work on the pull-out test[42] has shown that the strain in the debonded part of the fibre can be found from the balance of forces argument which gives rise to the expression[41]

$$
\varepsilon_{f}=\frac{2 \tau_{i}(i-x)}{r E_{f}}
$$

Equation 5

where $\tau_{l}$ is the frictional shear stress, $i$ is the point where a line fitted to the data in the debonded region intercepts the distance axis and the other symbols are as defined previously. The strain in the elastic part of the droplet can be given by modifying equation 2 to use the bonded, rather than total, length of the fibre. In figure 13 the curve at the highest load level has been fitted using these equations assuming that the frictional shear stress is $10.5 \mathrm{MPa}$ and that $\mathrm{n}$ is 0.07 . It can be seen from the figure that these equations fit the data reasonably well. It is interesting to note that the value of $\mathrm{n}$ is the same as that required to fit the data of figure 7 for a knife edge gap of 80 $\mu \mathrm{m}$, i.e. at a separation where the finite element analysis shows that there is little effect of the knife edges upon the shear stress distribution. Thus the strain data recorded for this test can be explained and fitted using the existing theory for the pull-out test. The value of the frictional shear stress obtained for this system is exactly the same as the average value obtained by Bannister et al from pull-out tests on high modulus Twaron fibres in a similar resin[42]. The shear yield stress of this resin has been found to be $43 \mathrm{MPa}[42]$. The interfacial shear stress data calculated at a fibre strain of $0.8 \%$ and shown in figure 13 are consistent with this as is the data for a sample with $1.7 \%$ fibre strain. The data obtained for the sample under a fibre strain of $1.1 \%$ lead to shear stresses close to the fibre end which are apparently greater than the shear yield stress for the matrix. This is probably due to fitting to the low number of data points and the 
comparatively high random error in them due to the difficulty in performing the measurements.

\section{Conclusions}

It has been clearly shown that by use of Raman spectroscopy the strain distribution in an embedded fibre during microbond tests can be measured. This has shed some light on the interfacial shear stress distribution in the embedded fibre. In contrast to the assumption normally made in the analysis of data from this micromechanical test the interfacial shear stress is not constant. At low applied loads the strain and shear stress distributions are much as would be expected from shear lag theory. At higher loads this is no longer true. In the example presented in this paper in figure 13 evidence of debonding can be observed. It can also be seen from the experimental data presented in figures 7 and 8, the finite element analysis of figure 10 and the values of $n$ required to fit the data to theory that the position of the grips which support the microdroplet is important and directly affects the interfacial shear stress distribution and its maximum value. The finite element analysis shows that once the knife edges are placed a few fibre diameters away from the fibre the stress distribution becomes insensitive to their position. If the knife edges are placed close to the fibre then the strain and stress distributions and in particular the maximum interfacial shear stress is very dependent upon gripping position. This is contradictory to the recommendations of Chou et al[43] who suggest that the knife edges should be placed close to the fibre. The data from the conventionally performed and analysed microbond test shows that the values derived for the average interfacial shear stress are much lower than the actual maximum shear stresses. The values obtained for the conventional test were not very dependent upon the position of the knife edge supports, even thought the Raman data shows this to be a critical factor controlling the shear stress distribution and maximum interfacial shear stress. It is clear from these observations that a method of data reduction which assumes that the interfacial shear stress is constant under all loading conditions is not appropriate. In none of the cases examined was the interfacial shear stress constant. Furthermore interfacial failure will not occur because of the presence of some average level of interfacial shear stress but due to the maximum interfacial shear stress being high enough to cause, for example, rupture of the interface or yielding of the matrix close to the interface. In fact it is now clear that the failure occurs 
in two stages as seen in figures 12 and 13. The strains and interfacial shear stresses increase, but the shape of the distribution remains the same as the external load is increased. Failure is then initiated, in this case by a debonding process, and this propagates along the fibre. The maximum interfacial shear stress is the stress at the point where the fibre enters the droplet just before the interface begins to fail. In the conventionally performed test the failure force is recorded. At this point the force consists of that which is required to increase the shear stress to its maximum plus the force necessary to propagate the failure along the interface. There are thus at least two sources of variation in the data presented in figures 3 to 5 . One is variation due to the effect of the position of the knife edges. If the droplet is not central between these then the stress concentration effect may vary from sample to sample. The second effect comes from the variation in the frictional strength of the interface from sample to sample as demonstrated for the similar pull-out test by Bannister et al [42]

It is now necessary to redefine the procedures used to gather the experimental data and for the calculation of interfacial shear stresses in the light of the observations presented here and elsewhere[42,44]. The shear lag type models do fit the strain distributions, but the force required to calculate the interfacial shear strength is not the failure load of the specimen. The force required is that at which the sample starts to fail. At this point the strain and interfacial shear stresses fit the shear lag type distributions and the maximum interfacial shear stress is reached, as noted above. In principle this can be obtained from careful analysis of the load-displacement curve since the compliance of the sample will change slightly at this point. This change in slope is not easy to detect and some recommendations for a technique which would allow this approach to be used have been made by one of the authors elsewhere[44]. In essence the suggested method is to use not one but two droplets. One of these would be restrained, the other displaced. The load-displacement curve would be recorded and the change in stiffness of the sample would indicate the load at which yielding or debonding occurred. This load could then be used to calculate the interfacial shear strength using a shear lag model. A similar suggestion has been made by Hampe and Marotzke [45]. 
Acknowledgements

The finite element modelling was undertaken using the LUSAS finite element modelling software supplied by FEA Ltd. 


\section{$\underline{\text { References }}$}

1. Kelly, A and Tyson, W.R. J. Mech. Phys. Solids, 13, 329 (1965)

2. Chua, P.S. and Piggott, M.R., Comp. Sci. Tech., 22, 33 (1985)

3. Favre, J.P. and Merienne, M.C., Int. J. Adhesion Adhesives, 1, 311 (1981)

4. Desarmot, G. and Favre, J.-P. Composites Science and Technology 42, 151 (1991)

5. Penn, L.S. and Lee, S.M., Fibre Sci Tech, 17, 91 (1982)

6. Marshall, $P$ and Price, J., Composites, 22(1), 53 (1991)

7. Broutman, L.J., Polymer Eng. Sci., 6, 263 (1966)

8. Pitkethly, M.J. and Doble, J.B., Composites, 21(5), 389 (1990)

9. Frazer, W.A., Ancker, F.H. and DiBennedetto, A.T., Proc 30th Conf. on Reinforced Plastics SPI section 22A, p.1, 1975

10. Broutman, L.J., Interfaces in Composites, ASTM STP 452, pp 27-41, 1969

11. Drzal, L.T., Rich, M.J. and Lloyd, P.F., J. Adhesion, 16, 133 (1983)

12. Gaur, U. and Miller, B., Comp. Sci. Tech., 34, 35 (1989)

13. Miller, B., Muri, P. and Rebenfeld, L., Comp. Sci. Tech., 28, 17 (1987)

14. Pitkethly, M.J., Favre, J.-P., Gaur, U., Jakubowski, J., Mudrich, S.F., Caldwell, D.L. Drzal, L.T., Nardin, M., Wagner, H.D., Di Landro, L., Hampe, A., Aristead, J.P., Desaeger, M. and Verpoest, I. Composites Science and Technology, 48, 205 (1993)

15. Wagner, H.D., Gallis, H.E. and Wiesel, E., J. Mater. Sci. 28, 2238 (1993)

16. Banbaji, J., Composites Science and Technology, 32, 183 (1988)

17. Piggott, M.R., Load Bearing Fibre Composites, Pergamon Press, Oxford, UK, (1980) p83

18. Day, R.J., Deformation and fracture of composites, Institute of Materials, 1993

19. Marotzke, C, Interfacial Phenomena in Composite Materials '91, Pub Butterworths, Ed. I. Verpoest and F.R. Jones, 1991, p69

20. Young, R.J. and Day, R.J. in 'Integration of Fundamental Polymer Science and Technology - 5, Ed. P.J. Lemstra and L.A. Kleintjens, Elsevier Applied Science London, in press.

21. Young, R.J., Lu D. and Day, R.J, Polymer International 24, (1991) 71.

22. Yang, X. Hu, X., Day, R.J. and Young, R.J., Journal of Materials Science. 27, 1409 (1992) 
23. Young, R.J., Day, R.J., Ang P.P., Stanford, J.L. and Hu, X, Proc.1st Int.Conf. on Deformation and Fracture of Composites, The Plastics and Rubber Institute, Manchester, $\underline{19}$, (1991).

24. Day, R.J. and Marquez, M. in Interfacial Phenomena in Composite Materials '91 edited by I. Verpoest and F.R. Jones, Butterworth-Heinemann Ltd., Oxford, 1991, pp65-68.

25. Galiotis, C., Robinson, I.M., Young, R.J., Smith, B.J.E., and Batchelder, D.N., Polym. Comm., 26, 354 (1985)

26. Young, R.J. and Day, R.J., British Polymer Journal, 21, 17 (1989).

27. Day, R.J. and Marquez, M. in Interfacial Phenomena in Composite Materials '91 edited by I. Verpoest and F.R. Jones, Butterworth-Heinemann Ltd., Oxford, 1991, pp65-68.

28. Andrews, MC, Day, RJ, Hu X and Young, R J, J. of Mat. Sci. Let. 11, 1344 (1992)

29. Gu. X.H, Day, R.J and Young, R.J Proc. 2nd Int.Conf. on Deformation and Fracture of Composites 1993.

30. Day, R.J. Proc. 2nd Int. Conf. on Deformation and Fracture of Composites 1993.

31. Andrews, M.C., Young, R.J. and Day, R.J., Proceedings sixth European Conference on Composite Materials, pub, Woodhead Publishing Ltd., p133$13 ? 1993$.

32. Andrews, M.C., Day, R.J., Hu, X. and Young, R.J. Composites Sci. and Tech., 48, 255 (1993)

33. Andrews, M.C., Young, R.J. and Day, R.J., in 'Developments in the Science and Technology of Composite Materials' Edited by A.R. Bunsell, A. Kelly and A. Massiah, Woodhead Publishing Ltd., Cambridge, 1993, p133.

34. Andrews, M.C., Day, R.J., Patrikis, A.K. and Young, R.J. Composites, 25 (1994) 745.

35. Penn, L.S. and Milanovich, F., Polymer, 20, 31 (1979)

36. Edwards, H.G.M. and Hakiki, S., Brit. Polym. J., 21, 505 (1989)

37. Kawabata, S, J. Textile Institute, 81(4), 432 (1980)

38. Baltussen, J.J.M. and Northolt, M.G., J. Rheology 41(3), 575 (1997)

39. Cox, H.L. J. Applied Physics, 3, 72 (1952) 
40. Takau, A and Arridge, R.G.C., J. Physics D: Applied Physics, 6, 2038 (1973)

41. Kelly, A and McMillan, N.H., Strong solids, Pub Oxford Science Publications, 1986

42. D.J. Bannister, Ph.D. , UMIST, 1996

43. Chou, C.T., Gaur, U. and Miller, B., Composites Science and Technology, 51(1), 111 (1994)

44. R.J. Day, Interfaces in Carbon and polymeric fibre composites, Proceedings of workshop held February1-2 1995, Kaiserslauten, Ed. H-J. Jacobasch, pp116126

45. A. Hampe and C. Marotzke, Journal of Reinforced Plastics and Composites, 16(4), 341 (1997) 


\section{Figures}

Figure 1. Schematic diagram of the experimental arrangement used to obtain debonding force versus embedded area data.

Figure 2. Schematic diagram of the apparatus used to perform the simulated microbond tests.

Figure 3. Plot of debonding force versus embedded area measured for Kevlar 49 fibres in Ciba Geigy LY5052 resin with a knife edge separation of $20 \mu \mathrm{m}$.

Figure 4. Plot of debonding force versus embedded area measured for Kevlar 49 fibres in Ciba Geigy LY5052 resin with a knife edge separation of $50 \mu \mathrm{m}$.

Figure 5. Plot of debonding force versus embedded area measured for Kevlar 49 fibres in Ciba Geigy LY5052 resin with a knife edge separation of $80 \mu \mathrm{m}$.

Figure 6. Calibration of rate of change of position of the $1610 \mathrm{~cm}^{-1}$ band in Kevlar with strain.

Figure 7. Strain distribution in droplets of approximately $500 \mu \mathrm{m}$ length at various knife edge separations.

Figure 8. Interfacial shear stress distribution in droplets of $500 \mu \mathrm{m}$ length at various knife edge separations calculated from the data of figure 7 .

Figure 9. Finite element mesh used in numerical modeling of the microbond test.

Figure 10. Strain distribution along the interface in a droplet of length $540 \mu \mathrm{m}$ calculated using a linear elastic finite element model. The curves were generated by moving the gripping position away from the fibre one node at a time and rerunning the analysis.

Figure 11. Strain distribution as a function of droplet length. Knife edge separation 80 $\mu \mathrm{m}$.

Figure 12. Strain distribution in a droplet of $440 \mu \mathrm{m}$ in length with knife edge 
separation of $50 \mu \mathrm{m}$ as a function of strain in loaded part of fibre. The solid lines are fits to the theory described in the text.

Figure 13. Interfacial shear stress distributions calculated from the data of figure 12 using the theory outlined in the text. 
Force

Fibre

\section{Knife edges}

Droplet

Figure 1 


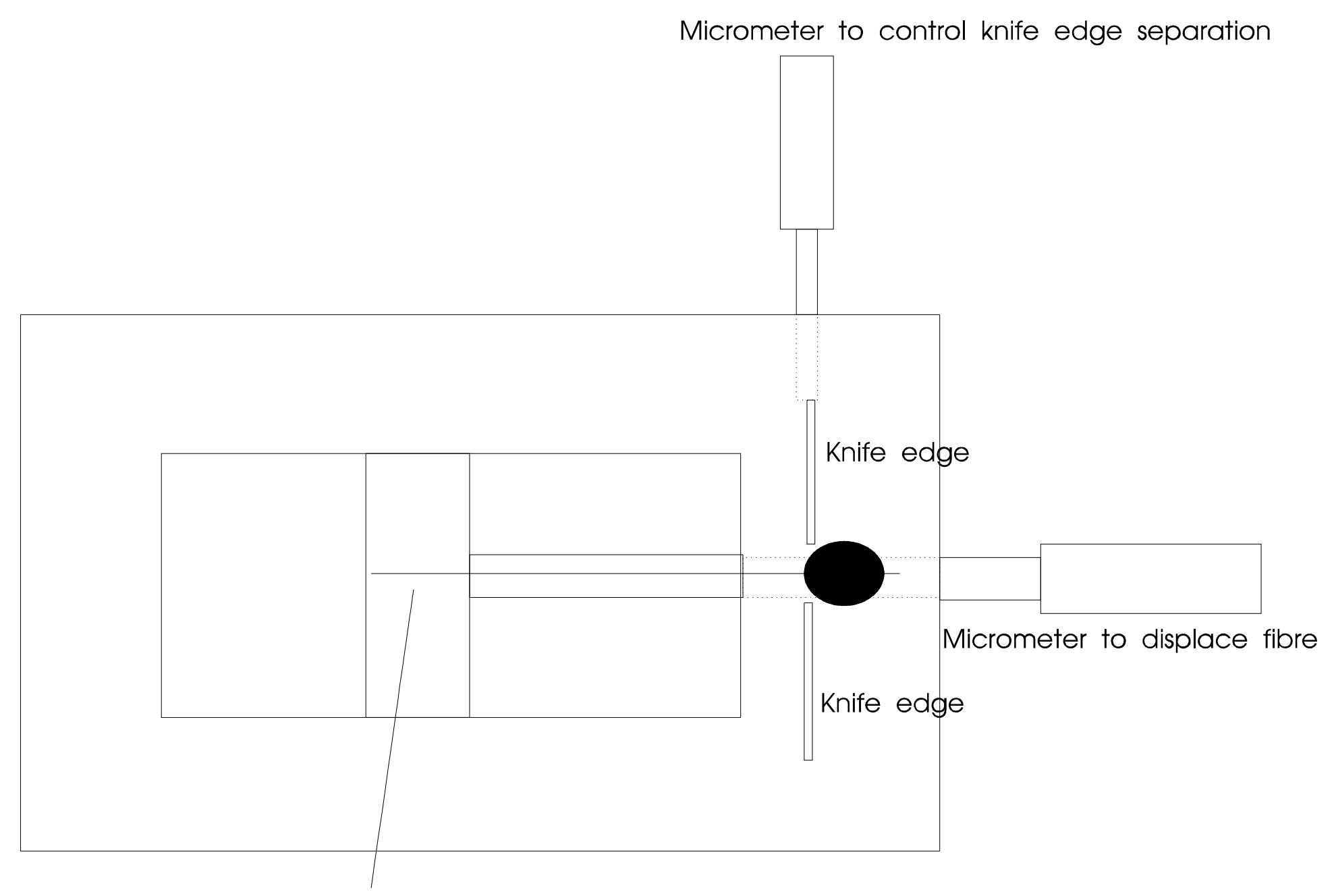

Fibre adhered to moving block

Figure 2 


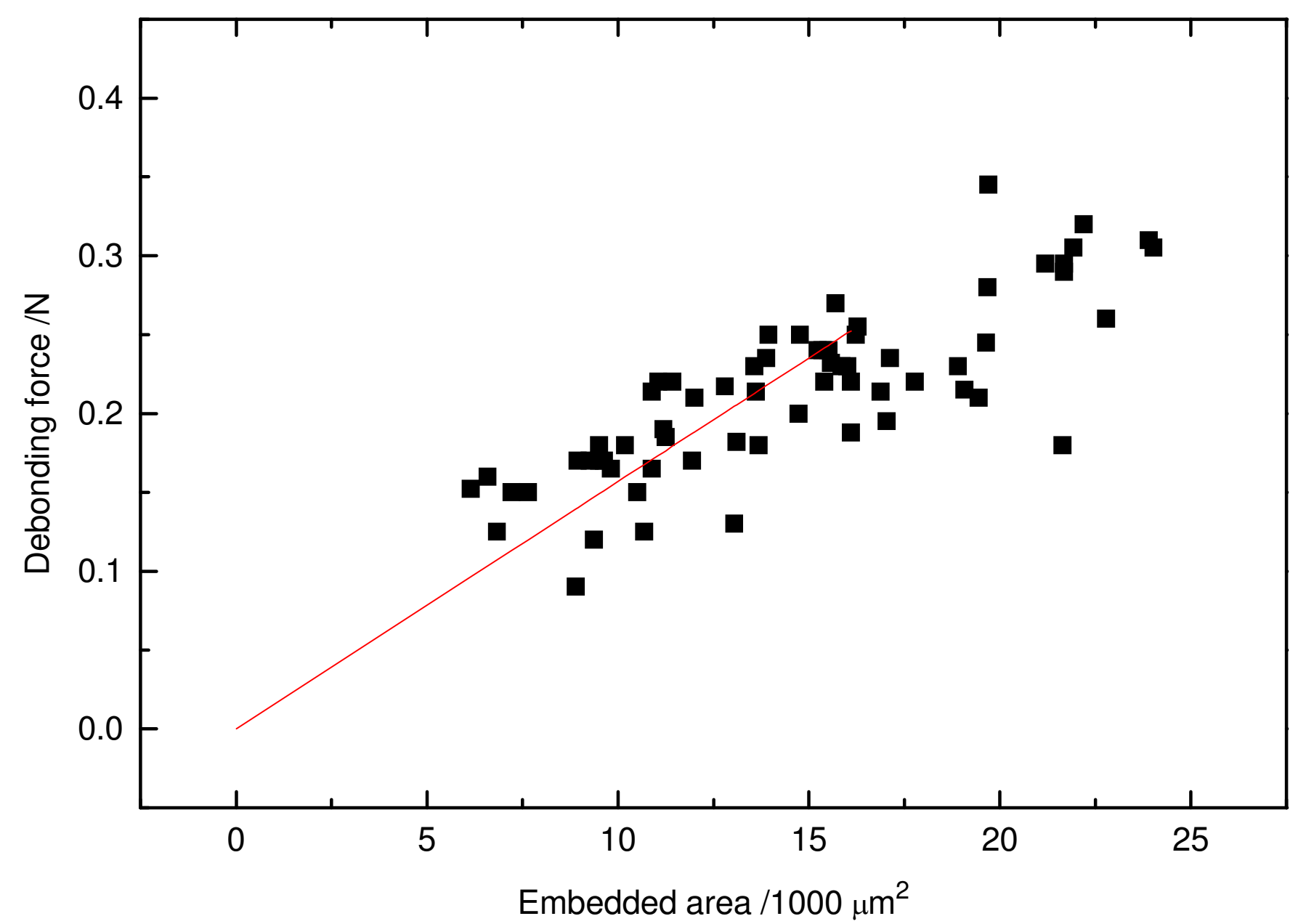

Figure 3 


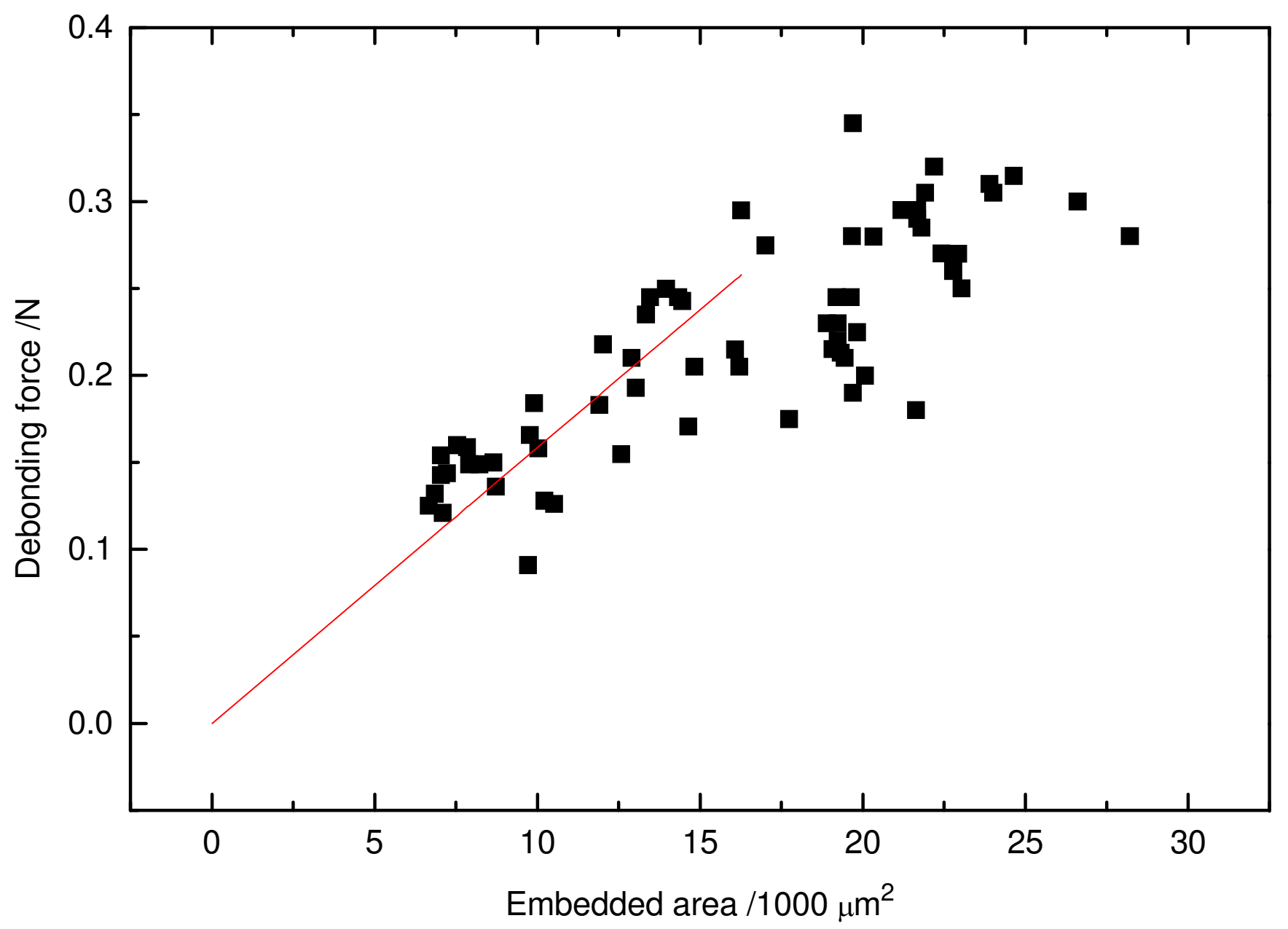

Figure 4 


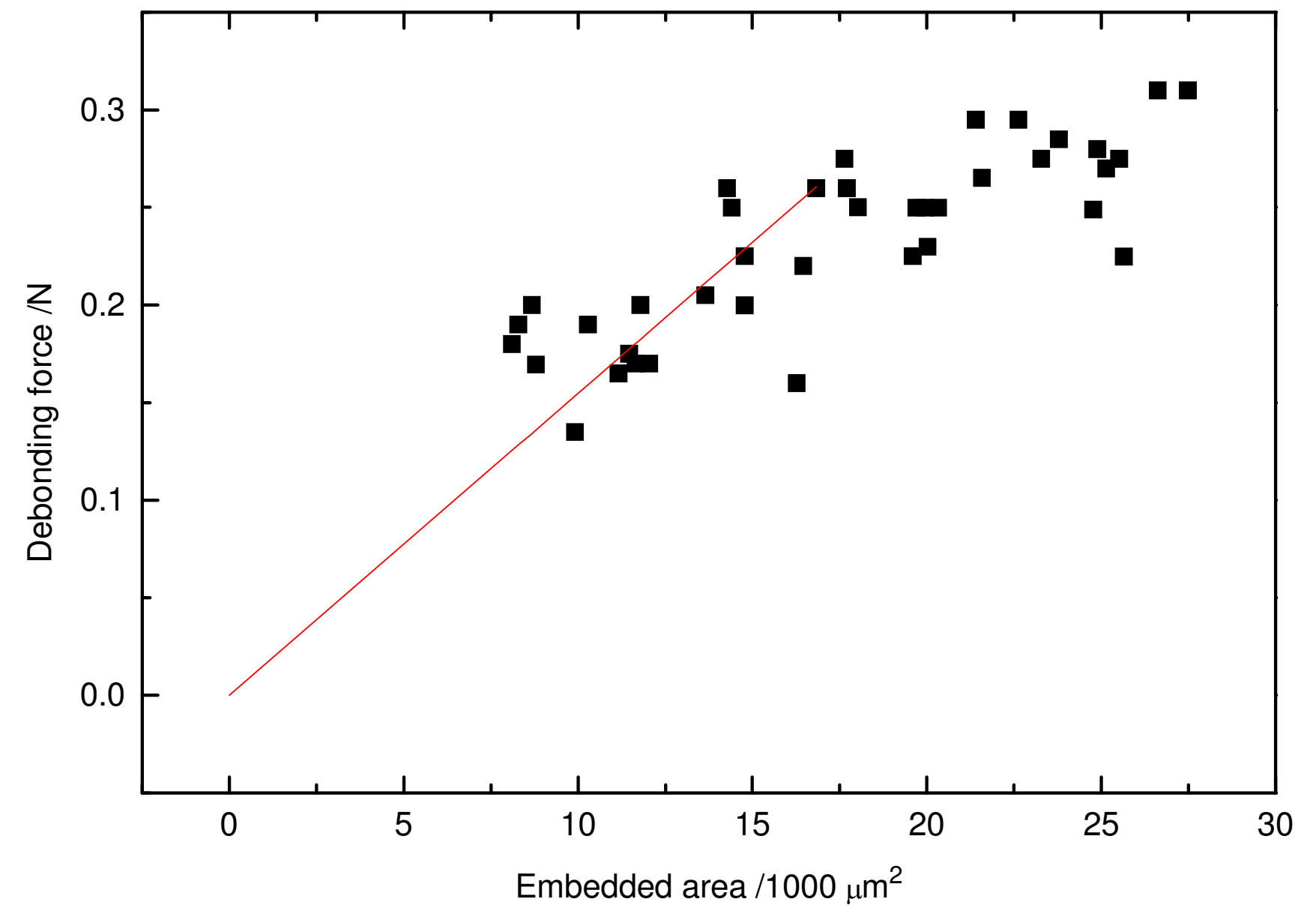

Figure 5 


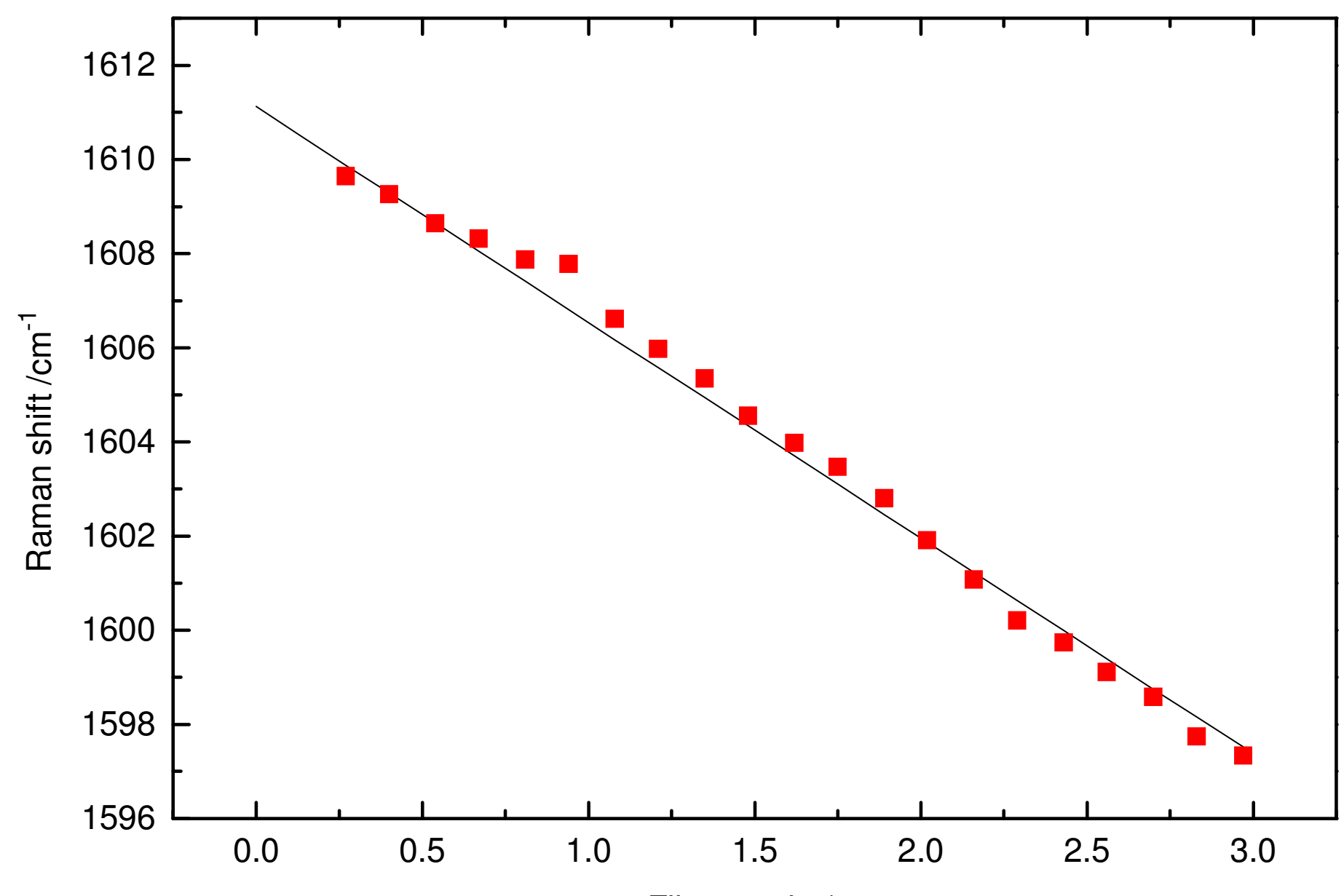

Fibre strain $/ \%$

Figure 6 


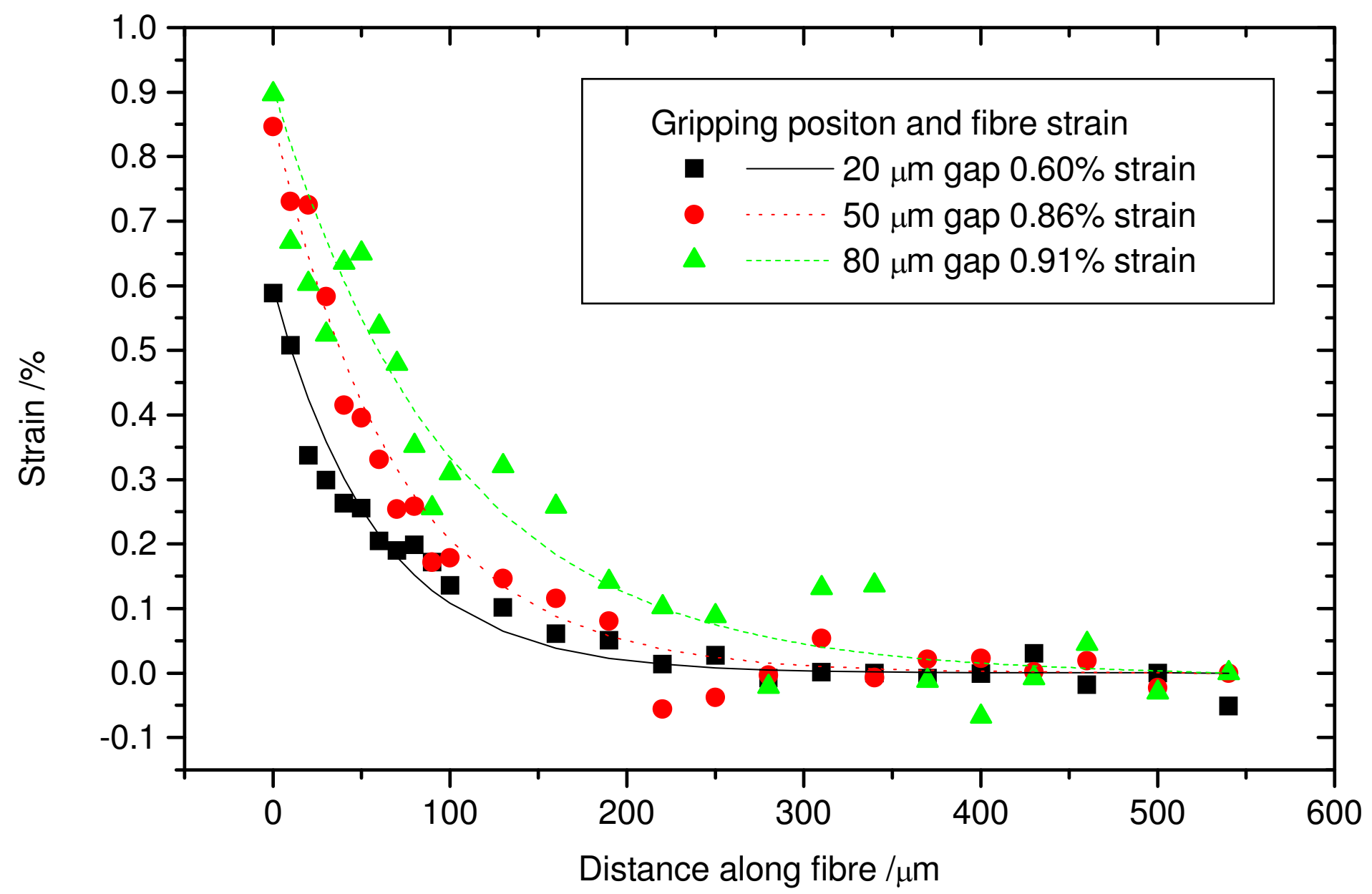

Figure 7 


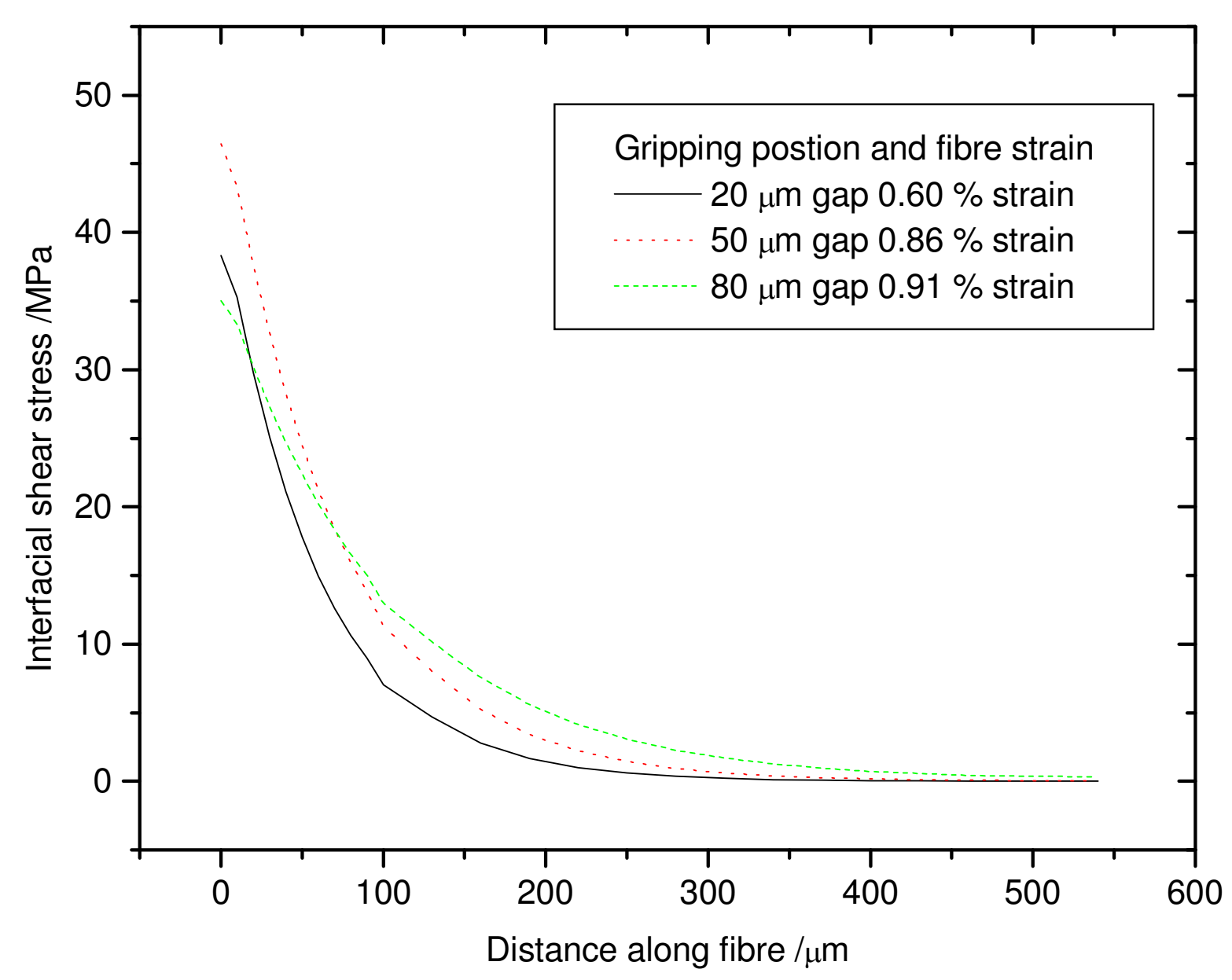

Figure 8 


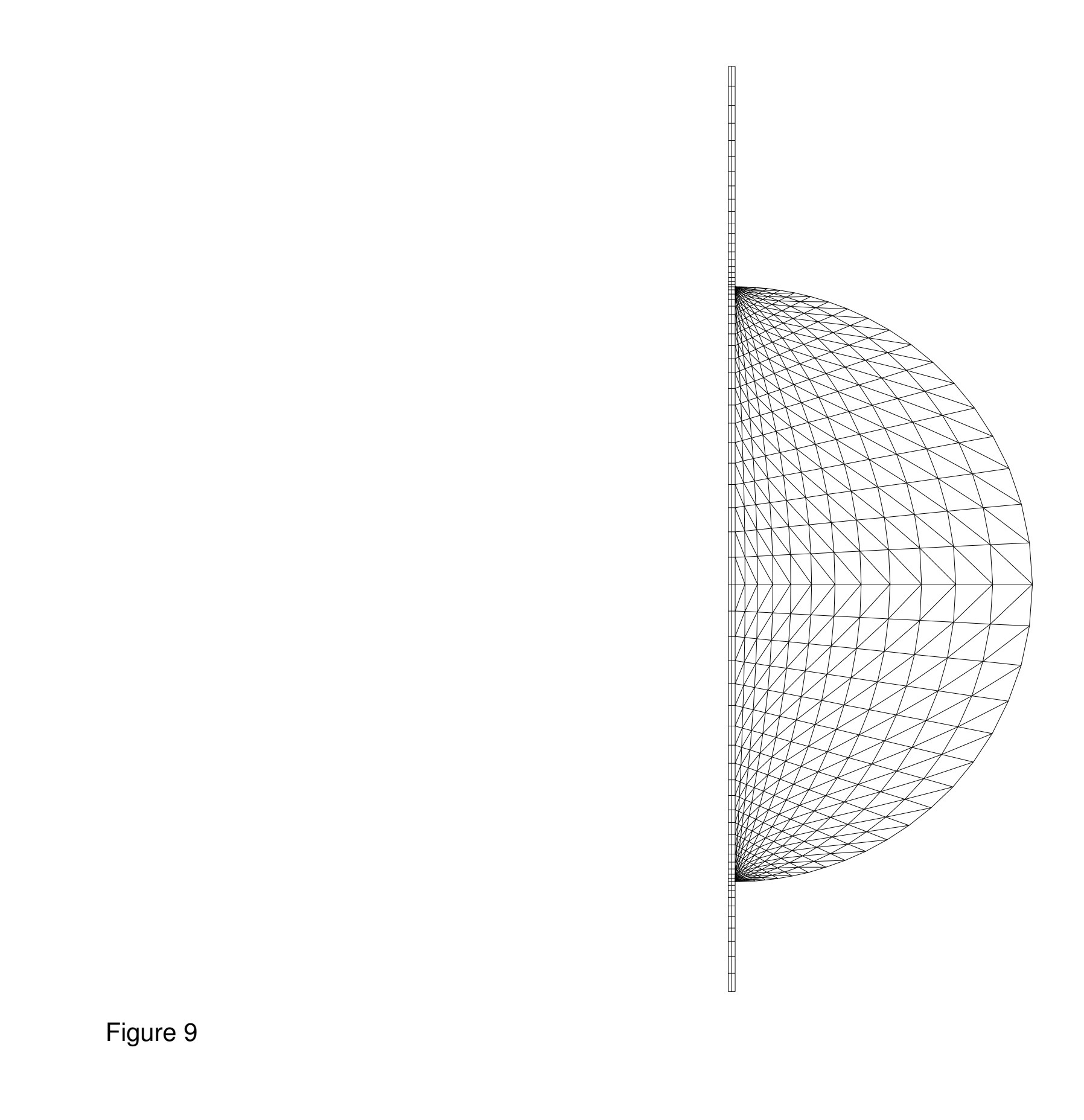




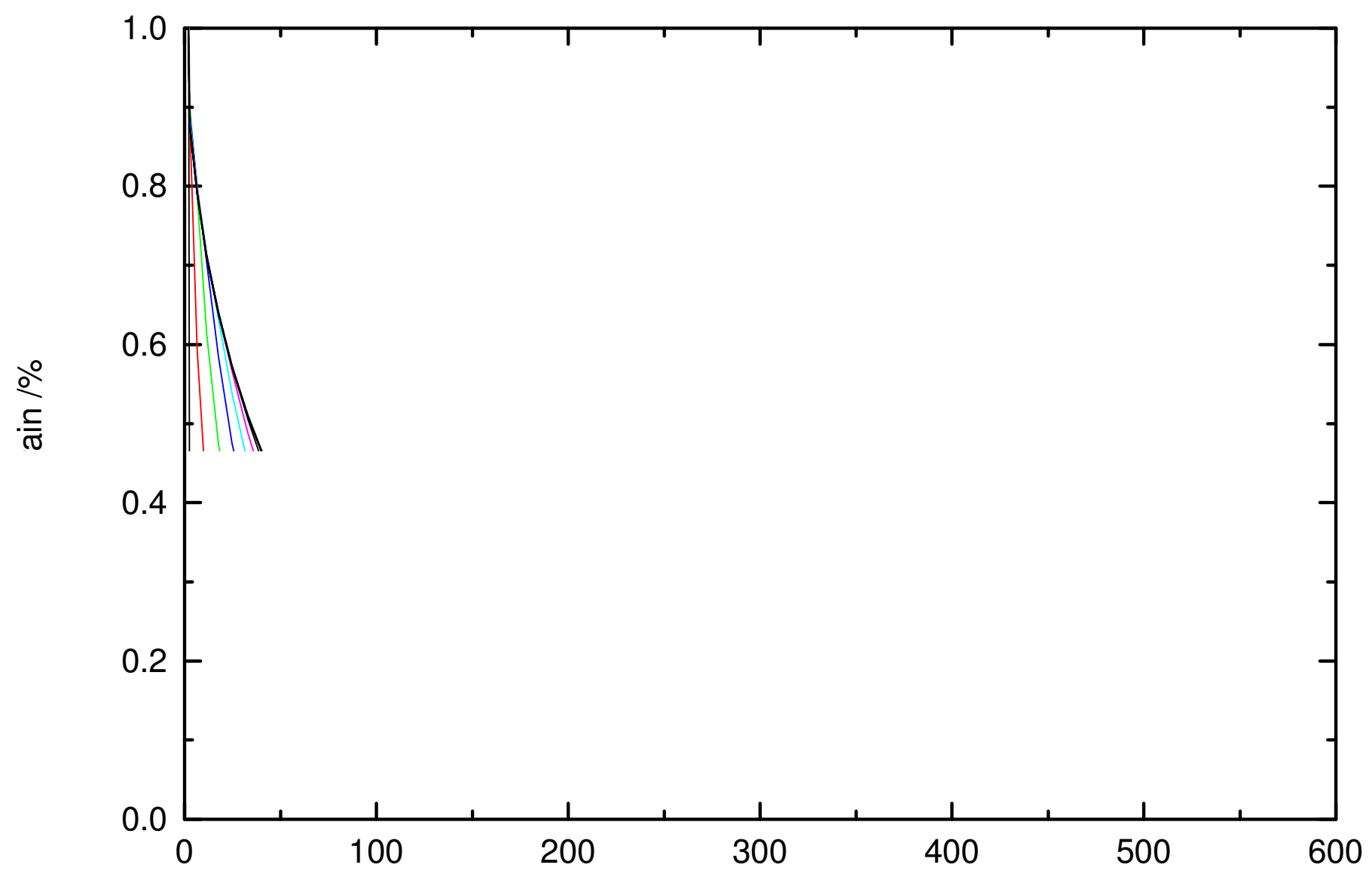

Figure 10 


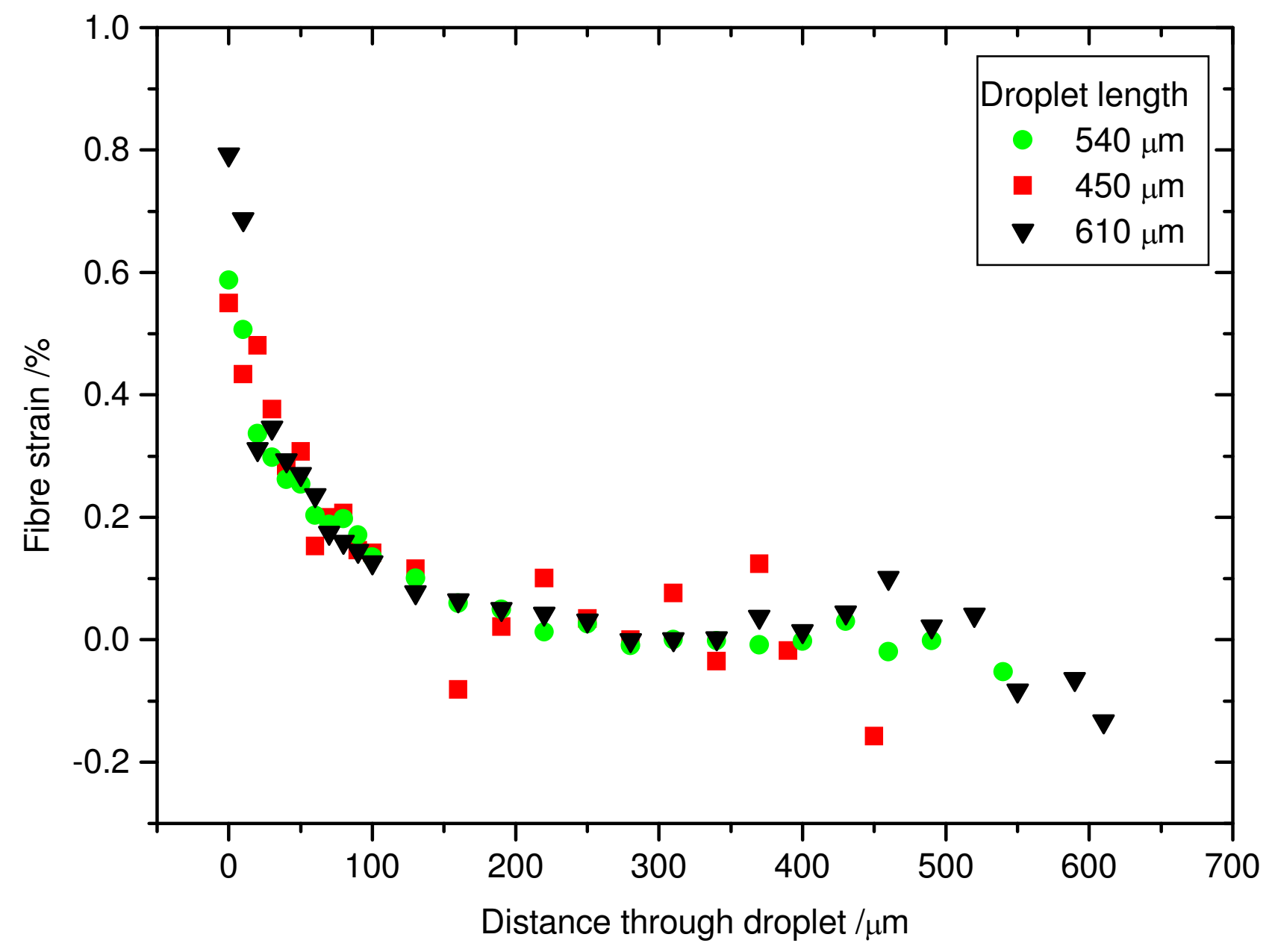

Figure 11 


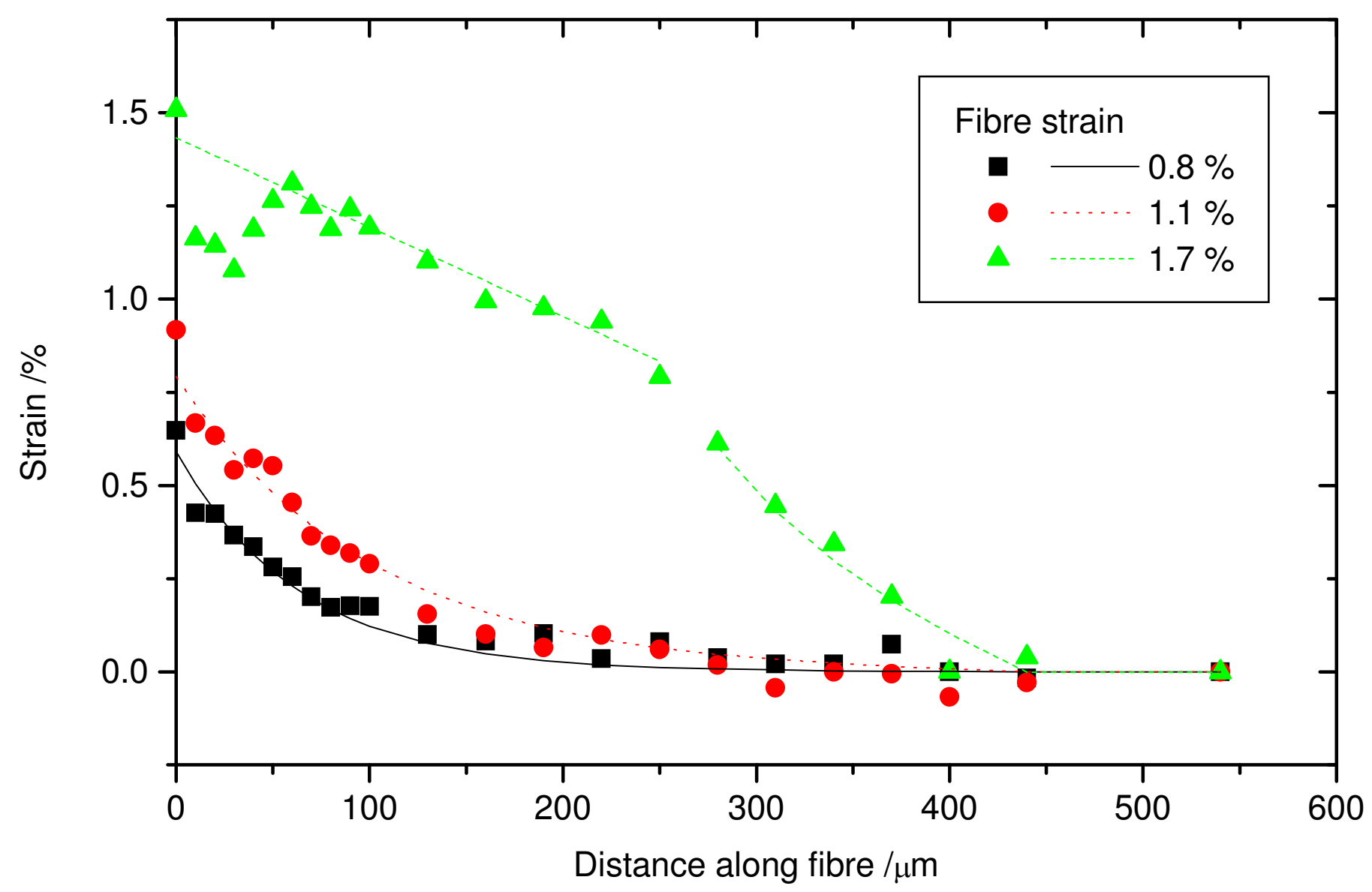

Figure 12 


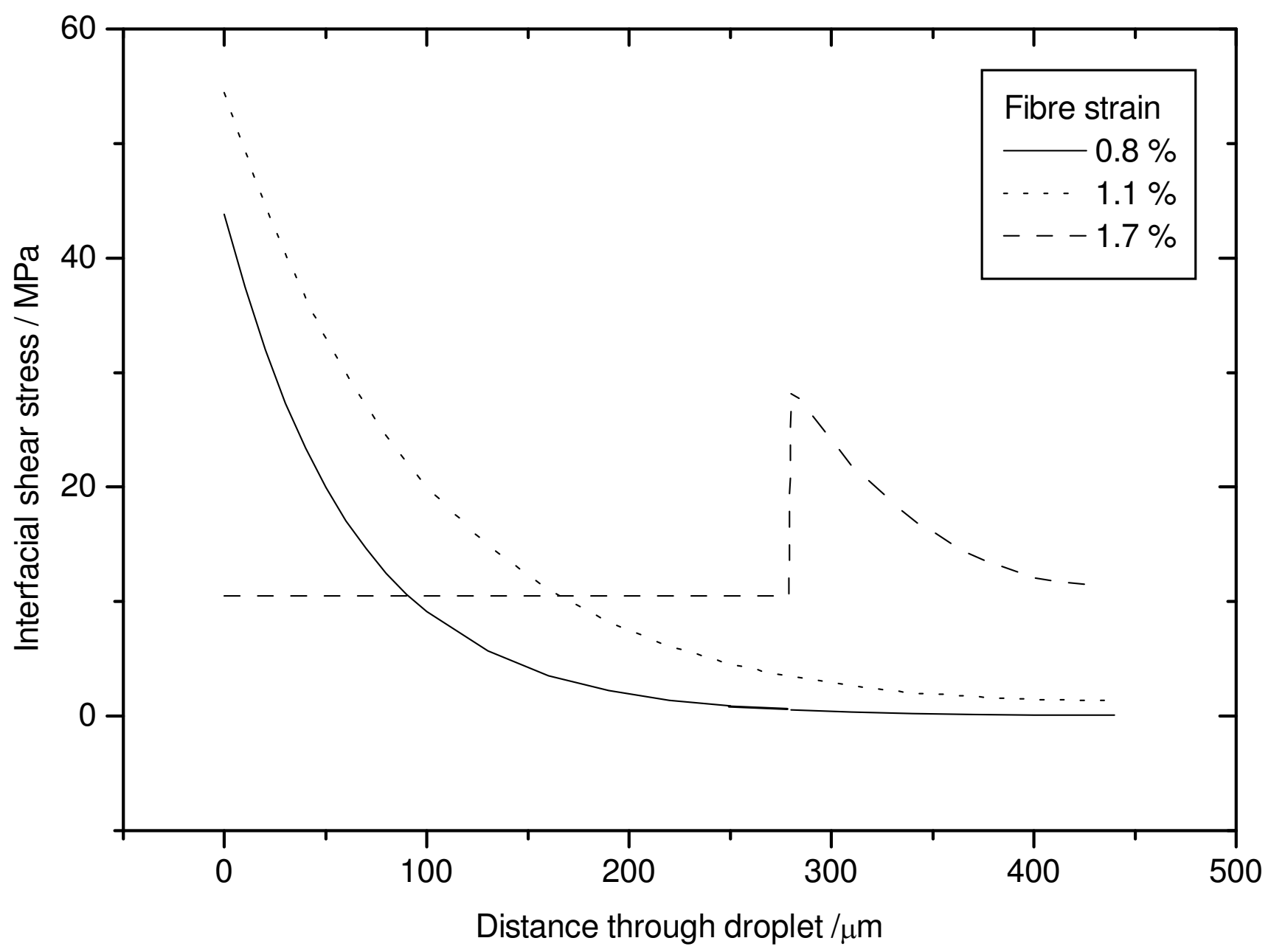

Figure 13 